\title{
COLOR CHANGES OF POST-DEBONDING WHITE SPOT LESION AFTER MICROABRASION TECHNIQUE WITH FLUORIDE AND CASEIN PHOSPHOPEPTIDE-AMORPHOUS CALCIUM PHOSPHATE APPLICATION
}

\author{
IRENE PRATAMI ANGRIAWAN ${ }^{1}$, HARU SETYO ANGGANI ${ }^{2 *}$, NADA ISMAH ${ }^{3}$
}

Department of Orthodontics, Faculty of Dentistry, Universitas Indonesia, Jakarta, Indonesia. Email: drg.irene@gmail.com

Received: 07 March 2018, Revised and Accepted: 25 March 2018

\section{ABSTRACT}

Objective: The prevalence of enamel demineralization among patients after orthodontic treatment is about $50 \%$, which begins with the formation of white spot lesions. The presence of these lesions causes esthetic problems. The aim of this study was to quantify the color changes in post-debonding white spot lesions after microabrasion technique with fluoride and casein phosphopeptide-amorphous calcium phosphate (CPP-ACP) application.

Materials and Methods: This study used 42 first premolar teeth that had been extracted, then were soaked for $96 \mathrm{~h}$ in a demineralization solution $\left(\mathrm{pH} 4,37^{\circ} \mathrm{C}\right)$ to form an artificial white spot lesions. Samples were randomly divided into three treatment groups (n=14): (A) Microabrasion technique only; (B) microabrasion technique with 10\% CPP-ACP paste application; and (C) microabrasion technique with 1.23\% APF gel application. All groups were assigned to $\mathrm{pH}$ cycling for 10 days. The color change was determined using spectrophotometer at 3 different time points, which were measured before and after production of the artificial white spot lesions, and after the artificial white spot lesions were treated.

Results: This study showed that there was a significant difference in the color of the artificial white spot lesions after microabrasion technique with CPP-ACP application.

Conclusion: Microabrasion technique with CPP-ACP application was giving better result in changing the color of white spot lesions than only microabrasion technique and microabrasion technique with fluoride application.

Keywords: Color change, White spot lesion, Microabrasion technique, Fluoride, Casein phosphopeptide-amorphous calcium phosphate.

(C) 2018 The Authors. Published by Innovare Academic Sciences PvtLtd. This is an open access article under the CC BY license (http://creativecommons. org/licenses/by/4. 0/) DOI: http://dx.doi.org/10.22159/ajpcr.2018.v11s1.26605

\section{INTRODUCTION}

Orthodontic treatment is a treatment for correcting malocclusions that will improve patient's mastication function, speech, and esthetic. Orthodontic treatment also enhances the patient's confidence [1]. However, in addition to these benefits, orthodontic treatment, especially with fixed orthodontic appliances, also has side effects which include damage to the enamel hard tissue and tooth-supporting tissues [2].

One of the most common enamel hard tissue damages that occur during and after orthodontic treatment is the demineralization of enamel. Several research reports show that the prevalence of enamel demineralization occurs in $50 \%$ of patients with fixed orthodontic treatment. Another study said that after 5-year post-orthodontic treatment, patients had incidence of a higher enamel opacity compared to the orthodontic-treated control group. The efforts to reduce the possibility of side effects of enamel demineralization are to educate patients and provide information about the importance of maintaining oral health during orthodontic treatment [2].

Email demineralization initially occurs when enamel porosity increased so that has a chalky white clinical appearance, up to the loss of its translucency. This appearance is called a white spot lesion. Conservative treatment to white spot lesions generally aims to remineralize the lesion with fluoride and calcium applications, which can penetrate into white spot lesions [3]. The use of mouthwash containing $0.05 \%$ of fluoride daily has been proven effective when the patient has adherence to the dentist's instructions [2,4]. The fluoride application is said to form fluorapatite on the enamel hard tissue structure. However, this fluorapatite can still be demineralized at a critical pH 4.5 [5]. Therefore, the other management of white spot lesions is developed by reactivating superficial enamel substrates through mechanical and chemical abrasion. One of the most studied methods for treating white spot lesions is the enamel remineralization using milk derivatives, which is casein phosphopeptide-amorphous calcium phosphate (CPP-ACP). The results of remineralized white spot lesions with CPP-ACP were considered better than with fluoride $[3,6]$.

While the management of white spot lesions is developing, microabrasion technique which was performed before fluoride or CPP-ACP application is found. This action is expected to be able to eliminate white spot lesions without involving any invasive restorative procedures. Whereas, fluoride and CPP-ACP applications will produce enamel remineralization as a corrective effort for white spot lesions [3].

The purpose of treating white spot lesions is to improve the quality of the enamel tissue that can be assessed from the hardness, surface smoothness, and color changes [7-9]. A research by Austin et al., in 2016, studied about the effects of demineralization and remineralization on enamel hardness and texture using confocal laser scanning microscope. The results of this study indicate that after the demineralization process, there is a decrease in hardness and a significant increase in enamel texture roughness. However, after a $6 \mathrm{~h}$ of remineralization, the email hardness has recovered as it was before demineralization. The texture of enamel also improved although not statistically significant [9].

Improving the quality of the enamel in white spot lesion is also assessed by the color change. White spot lesions are more chalk white than normal enamel tissue color which can disrupt the esthetic appearance. Therefore, enamel remineralization in the treatment of white spot lesions is expected to produce an improved color change or close to normal surrounding enamel tissue color. Previous findings revealed that the application of CPP-ACP compared with the application of fluoride produces a color difference in white spot lesions clinically, but not statistically significant. Research on color change in white spot enamel lesions after microabrasion techniques followed by fluoride 
or CPP-ACP applications has not been performed yet. Therefore, some research should be done to know the difference of color change in white spot lesion after fixed orthodontic treatment with microabrasion technique by fluoride and CPP-ACP application [4].

\section{RESEARCH METHODS}

This research is an experimental laboratory type research which was conducted in July 2017-August 2017. The research site is in the Dental Laboratory of Materials Science Dentistry, Faculty of Dentistry, University of Indonesia. The sample population in this study was the first premolar teeth that had been extracted. The subject of this study was the enamel surface of the maxillary first premolar tooth that met the inclusion criteria and had been extracted.

The sample size in each study group was obtained from the numerical comparative research formula of more than two unpaired groups; it was 14 samples for each group or a total sample of 42 dental specimens. The specimens were soaked for $96 \mathrm{~h}$ in a demineralization solution $\left(\mathrm{pH} 4,37^{\circ} \mathrm{C}\right)$ to form an artificial white spot lesions, and were randomly divided into three treatment groups ( $n=14)$ : (A) Microabrasion technique; (B) microabrasion technique with $10 \%$ CPP-ACP paste application; and (C) microabrasion technique with $1.23 \%$ acidulated phosphate fluoride (APF) gel containing 12,300 ppm of fluoride at pH 3. After the treatments, all groups were assigned to $\mathrm{pH}$ cycling for 10 days.

All groups received microabrasion treatment. First, mixed $0.04 \mathrm{~g}$ of $11 \%$ opalustre hydrochloric acid gel solution with $0.006 \mathrm{~g}$ of pumice for $10 \mathrm{~s}$ until it had a porridge-like consistency. Placed the mixture on the specimen surface using a microbrush and let it rest for $2 \mathrm{~min}$. After that, polished the mixture using rubber cup at a low-speed handpiece with rotational movement for $20 \mathrm{~s}$. Rinsed with water spray for $20 \mathrm{~s}$, then dried with air spray for $20 \mathrm{~s}$. The amount of opalustre and pumice gel which would be used on each specimen was weighed using Shimadzu AX 200 analytical balance so that each study specimen had the same material weight. Before polishing with low speed, a handpiece load calibration was performed so that each specimen got the same rotation pressure load which was 0.20 $\mathrm{g}$, the pressure load then was measured using a portable electronic scale:

- Group B: After microabrasion treatment, Group B received 0.005 g of CPP-ACP paste brand GC Tooth Mousse applied on enamel surface using cotton bud, with rest for 5 min. The application of CPP-ACP paste was done daily for 10 days. Before use, the amount of CPP-ACP that would be applied on each specimen was weighed using Shimadzu AX 200 brand analytical balance.

- Group C: After microabrasion treatment, Group C was given $0.005 \mathrm{~g}$ APF gel on the surface of enamel using cotton bud, and let it rest for 5 min. Before use, the amount of APF gel that would be applied on each specimen was weighed using Shimadzu AX 200 brand analytical balance.

After each different treatment, all groups received solution replacement

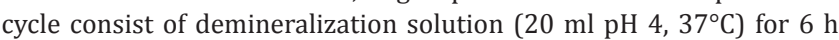
and replaced it with artificial saliva solution $\left(20 \mathrm{ml}, \mathrm{pH} 7,37^{\circ} \mathrm{C}\right)$ for 18 $\mathrm{h}$ every day. Solution replacement cycle was done for 10 days. After 10 cycles, the entire specimens were removed from artificial saliva solution and rinsed with water spray for $20 \mathrm{~s}$ and dried it with air spray for $20 \mathrm{~s}$.

The color change measurements were determined using a spectrophotometer at 3 different time points, which were before and after production of the artificial white spot lesions, and after the artificial white spot lesions were treated. The test was performed 3 times on the buccal surfaces in the gingival area of each specimen bracket and the average value was taken. The result of the calculation was recorded as $\Delta \mathrm{E}$ value of enamel color change.

\section{Statistical analysis method}

The research data were processed and tested statistically with the Special Package for the Social Sciences 17.0 program. The analysis performed is:
- Univariate analysis was performed to obtain the mean values, standard deviations, and maximum and minimum color change values in the three specimen groups.

- Bivariate analysis to analyze mean difference of initial and final color change value of the three treatment groups, was paired t-test (the normality test result is normal).

- Bivariate analysis to analyze the mean difference of white spot color change value between treatment group was done by Kruskal-Wallis test (the normality test result is not normal). Post-hoc statistical tests are performed by Mann-Whitney test (the normality test result is not normal).

\section{RESULT}

Univariate statistical tests were performed to obtain the mean values and standard deviations of white spot lesion color change values, after which the Shapiro-Wilk normality test was performed. Normality test results show all data are normally distributed (Table 1). There was no significant difference in the color changes of white spot lesions after orthodontic treatment before and after microabrasion techniques (Table 2). There is a difference in color change in white spot lesion after orthodontic treatment before and after CPP-ACP application (Table 2). There was no significant difference in the color changes of white spot lesion after orthodontic treatment in a group of microabrasion techniques with Fluor application (Table 2).

The result of Kruskal-Wallis test shows the value $\mathrm{p}=0.02 \quad(\mathrm{p}<0.05)$, so the null hypothesis is rejected. Then tested by Mann-Whitney post-hoc statistic, the result of the test between the treatment group of microabrasion technique and microabrasion technique with CPP-ACP $p=0.007(p<0.05)$, which means there is a significant difference of color change of white spot lesion between microabrasion techniques and microabrasion techniques with CPP-ACP. $p$ value in the test between the microabrasion treatment group and the microabrasion technique with Fluor application showed $\mathrm{p}=0.154$ ( $\mathrm{p}>0.05)$, which means no significant difference in color of white spot lesion between after microabrasion technique and microabrasion technique with Fluor application. $p$ value in the test between the treatment group of microabrasion technique with CPP-ACP and microabrasion technique with Fluor application showed $p=0.129(p>0.05)$, meaning there was no significant difference in white spot color between after microabrasion technique with CPPACP and microabrasion techniques with Fluor application. The result of Kruskal-Wallis and post-hoc Mann-Whitney test between groups can be seen in Tables 3 and 4 .

\section{DISCUSSION}

The formation of an artificial white spot lesion in this study was consistent with that of Kumar in 2008 in his research on the effects of CPP-ACP on the remineralization of an artificial caries lesion [10]. All the email specimens in this study were treated with a random sampling system. Specimens in Group A were only microabrasion, Group B was performed with microabrasion with CPP-ACP application, and Group C was performed with microabrasion with Fluor application. White spot lesion color repair is indicated by a large reduction of $\Delta \mathrm{E}$ values.

In the group of samples with microabrasion technique, the median value of $\Delta \mathrm{E}$ reduction was $0.7832(-1.698-4.457)$ unit, in the sample group with microabrasion technique with CPP-ACP application obtained the median value of $\Delta \mathrm{E}$ reduction of $1.7863(-4.090-0.956)$ units, and in groups with microabrasion techniques accompanied by Fluor application obtained a median value of $\Delta \mathrm{E}$ reduction of 0.1928 $(-6.059-1.614)$ units. It was observed that the largest white spot lesion color change was in the sample group treated with microabrasion technique with CPP-ACP application, followed by a group of samples treated with microabrasion technique, then a group of microabrasion techniques with Fluor application.

In this research, it can be seen that median $\Delta \mathrm{E}$ value after microabrasion technique is $0.7832(-1.698-4.457)$ unit, which means white spot 
Table 1: Descriptive test results (mean, standard intersection, and data normality) discoloration of early and late white spot lesions

\begin{tabular}{|c|c|c|c|c|c|}
\hline \multirow[t]{2}{*}{ Groups } & \multirow[t]{2}{*}{$\mathbf{n}$} & & \multirow{2}{*}{$\begin{array}{l}\text { Color change } \\
\text { Mean } \pm \text { SD }\end{array}$} & \multicolumn{2}{|c|}{ Normality test } \\
\hline & & & & Shapiro & Wilk (p) \\
\hline \multirow[t]{2}{*}{ A } & 14 & $\Delta \mathrm{E}_{\text {before }}$ & $7.3622 \pm 3.47283$ & $0.491^{*}$ & $(>0.05)$ \\
\hline & & $\Delta \mathrm{E}_{\mathrm{after}}$ & $8.3460 \pm 4.10146$ & $0.362^{*}$ & $(>0.05)$ \\
\hline \multirow[t]{2}{*}{ B } & 14 & $\Delta \mathrm{E}_{\text {before }}$ & $7.5564 \pm 2.59232$ & $0.120 *$ & $(>0.05)$ \\
\hline & & $\Delta \mathrm{E}_{\text {after }}^{\text {bere }}$ & $6.0874 \pm 2.47287$ & 0.939* & $(>0.05)$ \\
\hline \multirow[t]{2}{*}{$\mathrm{C}$} & 14 & $\Delta \mathrm{E}_{\text {before }}$ & $6.3266 \pm 3.03033$ & $0.653^{*}$ & $(>0.05)$ \\
\hline & & $\Delta \mathrm{E}_{\text {after }}^{\text {bere }}$ & $5.6249 \pm 2.52586$ & $0.096^{*}$ & $(>0.05)$ \\
\hline
\end{tabular}

${ }^{*} \mathrm{p}>0.05$ : Data normally distributed. Information: A group:

A microabrasion technique, B group: A microabrasion technique+CPP-ACP,

C group: A microabrasion technique+fluoride. SD: Standard deviation,

CPP-ACP: Casein phosphopeptide-amorphous calcium phosphate

Table 2: Comparative analytic pairwise t-test results discoloration of white spot lesions before and after treatments

\begin{tabular}{|c|c|c|c|c|}
\hline \multirow[t]{2}{*}{ Groups } & \multirow[t]{2}{*}{$\mathbf{n}$} & & Color change & \multirow[t]{2}{*}{ p value } \\
\hline & & & Mean \pm SD & \\
\hline A & 14 & $\begin{array}{l}\Delta \mathrm{E}_{\text {before }} \\
\Delta \mathrm{E}_{\text {after }}\end{array}$ & $\begin{array}{l}7.3622 \pm 3.47283 \\
8.3460 \pm 4.10146\end{array}$ & 0.074 \\
\hline B & 14 & $\begin{array}{l}\Delta \mathrm{E}_{\text {before }}^{\text {ater }} \\
\Delta \mathrm{E}_{\text {after }}\end{array}$ & $\begin{array}{l}7.5564 \pm 2.59232 \\
6.0874 \pm 2.47287\end{array}$ & $0.007^{*}$ \\
\hline $\mathrm{C}$ & 14 & $\begin{array}{l}\Delta \mathrm{E}_{\text {before }}^{\text {ater }} \\
\Delta \mathrm{E}_{\text {after }}\end{array}$ & $\begin{array}{l}6.3266 \pm 3.03033 \\
5.6249 \pm 2.52586\end{array}$ & 0.290 \\
\hline
\end{tabular}

${ }^{*} \mathrm{p}<0.05=$ Significantly different. SD: Standard deviation

change is not visually visible. Microabrasion was performed by applying $18 \%$ hydrochloric acid or $37 \%$ phosphoric acid and pumice paste in white spot lesions, which then eliminated about $100 \mu \mathrm{m}$ either through abrasion or erosion. Research conducted by Pliska on the effect of microabrasion techniques accompanied by CPP-ACP applications reported the result that treatment of white spot lesions with microabrasion techniques provides good results in dealing with white spot lesions [3]. Alexander mentions that the natural remineralization of white spot lesions is almost impossible because the mineral of the tooth is in equilibrium with the environment. Natural remineralization may occur possibly because the acid attack of the plaque is reduced or lost after the fixed orthodontic device is removed, so demineralization stops. However, the loss of plaque accumulation alone is insufficient to obtain a perfect white spot lesion repair. Loss of plaque accumulation may also increase the risk of a secondary lesion formed, lasting from 5 to 12 years. In other words, it takes a remineralization agent to get into the lesion and improve the appearance of the color of the white spot lesion [11-12].

Changes in the value of $\Delta \mathrm{E}$ in the sample group with microabrasion techniques with CPP-ACP applications differed significantly from the sample groups with microabrasion techniques alone. These results support several other studies, suggesting the need of remineralization agent applications and invasive action in the form of microabrasion techniques to repair the inside of the white spot lesion for the better esthetic results. The mean value of $\Delta \mathrm{E}$ after microabrasion technique with CPP-ACP application shows that the white spot color corrected closer to the initial email color. This seems to be due to the CPP-ACP ability to fill in the email subsurface. According to Reynolds who examines CPP-ACP as a remineralization agent, CPP-ACP works by increasing the levels of calcium and phosphate ions in subsurface lesions and can be further enhanced by the presence of fluorine ions. According to Reynolds, the early application of CPP-ACP is beneficial in natural repairs because the nanoclusters of CPP-ACP are smaller in size to reach the demineralized subsurface area through a remineralized outer surface layer. Such remineralization system enables the improvement of white spot lesions esthetically [13]. The CPP-ACP used in the present study is in a mousse preparation, ready to be used for professional
Table 3: Comparison of discoloration of white spot lesions after treatment

\begin{tabular}{llll}
\hline Groups & n & $\begin{array}{l}\text { Median } \\
\text { (minimum-maximum) }\end{array}$ & p value \\
\hline Microabrasion & 14 & $0.7832(-1.698-4.457)$ & $0.020^{*}$ \\
Microabrasion+CPP-ACP & 14 & $1.7863(-4.090-0.956)$ & \\
Microabrasion+fluor & 14 & $0.1928(-6.059-1.614)$ & \\
\hline
\end{tabular}

${ }^{*} \mathrm{p}<0.05=$ Significantly different. CPP-ACP: Casein phosphopeptide-amorphous calcium phosphate

Table 4: Results of the post-hoc Mann-Whitney test

\begin{tabular}{lll}
\hline Groups & Groups & $\begin{array}{l}\text { Post-hoc Mann-Whitney } \\
\text { test (p) }\end{array}$ \\
\hline A & B & $0.007^{*}$ \\
& C & 0.154 \\
B & C & 0.129 \\
\hline
\end{tabular}

${ }^{*} \mathrm{p}<0.05$ : Significantly different, A group: A microabrasion technique, B group: A microabrasion technique+CPP-ACP, C group: A microabrasion technique+fluoride. CPP-ACP: Casein phosphopeptide-amorphous calcium phosphate

use or by the patient himself for daily use. We applied CPP-ACP once in every 24 hours during the first 10 days of the study, simulating the daily use by the patient. In a recent study conducted by Yuan, CPP-ACP did not provide any significant change in the color of post-debonding white spot lesions. This is probably because the CPP-ACP application was applied only 1 time with follow-up after 6 weeks [14].

The differences in the value of $\Delta \mathrm{E}$ obtained after microabrasion technique with Fluor application are $0.1928(-6.059-1.614)$ unit which means that the white spot color improvement is not significant visually. The low $\mathrm{pH}$ environment of the fluorine preparation facilitated the formation of fluoroapatite. It is known from Geiger's study that the level of adherence of orthodontic patients in daily fluoride mouthwashes was only 13\% [15]. Ogaard (1988) suggests that direct application of high concentrations Fluor in white spot lesions would provide poorly esthetic results. The outermost surface of enamel will undergo prior remineralization and even hypermineralization occurs and inhibit the movement of Fluoride ions to reach sub-surface lesions, thus affecting the reflection of light falling on the hard surface of the enamel. In other words the opaque white look will remain on the surface of the email [15-17].

In this study, it was found that white spot color difference ( $\Delta \mathrm{E}$ reduction) between after microabrasion technique with Fluor application with after microabrasion technique with CPP-ACP application did not differ significantly statistically. Bröchner et al. mentioned that the results of lesion repair from the remineralization agent were obtained over a longer period of time. Brochner (2011) performed an in vivo longitudinal study with follow up data for 4 weeks after treatment and concluded that the results of lesion repair from the remineralization agent will be significant after a longer period of time [18].

\section{CONCLUSION}

There was no significant change in surface enamel color of postdebonding white spot lesion with microabrasion treatment technique. There was a significant change in surface enamel color of post-debonding white spot lesion with microabrasion technique and CPP-ACP application. There was no significant change in surface enamel color of post-debonding white spot lesion with microabrasion technique and Fluor application. There was a significant difference of surface enamel color of post-debonding white spot lesion between microabrasion technique, microabrasion technique with CPP-ACP application, and microabrasion technique with Fluor application. Based on this research, microabrasion technique with CPP-ACP application has better clinical and statistical benefit compared to 
microabrasion technique and microabrasion technique with Fluor application.

\section{ACKNOWLEDGMENT}

The publication of this study was supported by University of Indonesia.

\section{REFERENCES}

1. Brook PH, Shaw WC. The development of an index of orthodontic treatment priority. Eur J Orthod 1989;11:309-20.

2. Ellis PE, Benson PE. Potential hazards of orthodontic treatment-What your patient should know. Dent Update 2002;29:492-6.

3. Pliska BT, Warner GA, Tantbirojn D, Larson BE. Treatment of white spot lesions with ACP paste and microabrasion. Angle Orthod 2012;82:765-9.

4. Karabekiroğlu S, Ünlü N, Küçükyilmaz E, Şener S, Botsali MS, Malkoc S, et al. Treatment of post-orthodontic white spot lesions with CPP-ACP paste: A three year follow up study. Dent Mater J 2017;36:791-7.

5. Proffit WR, Fields HW, Sarver DM. Malocclusion and dentofacial deformity in contemporary society. In: Proffit WR, Fields HW, Sarver DM, editors. Contemporary Orthodontics. $5^{\text {th }}$ ed. St. Louis: Elsevier; 2013. p. 2-5.

6. Arruda AO, Behnan SM, Richter A. White-spot lesions in orthodontics: Incidence and prevention. Contemporary approach to dental caries. Angle Orthod 2012:313-32.

7. Fejerskov O, Nyvad B, Kidd EA. Clinical appearances of caries lesions. In: Fejerskov O, Kidd E, editors. Dental Caries: The Disease and its Clinical Management. Oxford: Blackwell Munksgaard; 2008. p. 8-18.

8. Safitri NM, Anggani HS, Purwanegara MK, Sumardi S. Enamel surface quality improvement in white spot lesions after orthodontic treatment using a microabrasion technique with fluoride or calcium phosphopeptide-amorphous calcium phosphate application. Int J Appl Pharm 2017;9:114-6.

9. Austin RS, Giusca CL, Macaulay G, Moazzez R, Bartlett DW. Confocal laser scanning microscopy and area-scale analysis used to quantify enamel surface textural changes from citric acid demineralization and salivary remineralization in vitro. Dent Mater 2016;32:278-84.

10. Kumar VL, Itthagarun A, King NM. The effect of casein phosphopeptideamorphous calcium phosphate on remineralization of artificial carieslike lesions: An in vitro study. Aust Dent J 2008;53:34-40.

11. Alexander SA, Ripa LW. Effects of self-applied topical fluoride preparations in orthodontic patients. Angle Orthod 2000;70:424-30.

12. Joshi M, Bolmal U, Dandagi P. Formulation and evaluation of cefuroxime axetil sol gel for periodontitis. Int J Pharm Pharm Sci 2014:498-503. ISSN 0975-1491.

13. Reynolds EC. Calcium phosphate-based remineralization systems: Scientific evidence? Aust Dent J 2008;53:268-73.

14. Yuan H, Li J, Chen L, Cheng L, Cannon RD, Mei L, et al. Esthetic comparison of white-spot lesion treatment modalities using spectrometry and fluorescence. Angle Orthod 2014;84:343-9.

15. Geiger AM, Gorelick L, Gwinnett AJ, Benson BJ. Reducing white spot lesions in orthodontic populations with fluoride rinsing. Am J Orthod Dentofacial Orthop 1992;101:403-7.

16. Ogaard B, Rolla G, Arends J. Orthodontic appliances and email demineralization: Lesion development. Am J Orthod Dentofac Orthop 1988;94:68-73.

17. Radhika Maniyar, Umashankar GK. Effectiveness of spirulina mouthwash on the reduction of dental plaque and gingivitis: a clinical study. Int J Pharm Pharm Sci 2017;9(7):136-139.

18. Bröchner A, Christensen C, Kristensen B, Tranæus S, Karlsson L, Sonnesen L, et al. Treatment of post-orthodontic white spot lesions with casein phosphopeptide-stabilised amorphous calcium phosphate. Clin Oral Investig 2011;15:369-73 